\title{
Effects of spark assist on HCCI combustion
}

\begin{abstract}
HCCI (homogeneous charge compression ignition) combustion is initiated by compression temperature and is independent of spark discharge. However, spark discharge can be applied under certain conditions to achieve hybrid combustion, where combustion by flame propagation is followed by auto-ignition of the unburned mixture. Spark assist can be applied to improve combustion stability at low loads or to reduce pressure rise rates under high load regime. In the current study variable spark ignition timing was applied for stoichiometric HCCI combustion, achieved using negative valve overlap technique. Under investigated conditions increase of nitrogen oxides emissions, due to flame propagation, was not observed. To provide more insight into combustion evolution, double Wiebe function was fitted to experimental heat release rates. It was found that only less than $10 \%$ of mixture was burned by flame propagation, even for very advanced spark discharge.
\end{abstract}

Key words: HCCI, spark assist, double Wiebe

\section{Introduction}

Homogeneous charge compression ignition (HCCI) is an innovative combustion system, which can be applied in piston engines. Air-fuel mixture is prepared early, thus is well premixed before combustion occurs. The combustion is initiated by temperature during the compression process. Auto-ignition is spontaneous and appears in multiple sites within the combustion chamber. It results in low temperature combustion, as unburned and burned mixture zones, typical for other combustion systems, do not appear $[6,9,13]$. Volumetric combustion of premixed charge produces extremely low concentrations of nitrogen oxides as well as particulates. In principle, there is no necessity to use advanced exhaust aftertreatment systems, such as selective catalytic reduction or particulate filters [5]. HCCI engines can be equipped with standard three-way catalytic converters, despite lean combustion. Additionally, HCCI engines offer higher thermal efficiency than current spark ignition engines [13].

Conversion of spark ignition engines into HCCI requires introduction of additional energy into the cylinder, to enable auto-ignition of high octane number fuels. This can be achieved by: (i) increasing of compression ratio, (ii) increasing of intake temperature, or (iii) using the exhaust energy [13]. It should be noted, that HCCI combustion at high load regime results in unacceptable pressure rise rates (PRRs). Thus, gasoline engines have to be operated as spark ignition under high load regimes. The need for switching between two combustion modes limits compression ratio [5]. Thus, utilizing exhaust energy to invoke combustion under low compression ratios appears to be the most attractive from the point of view of practical implementations. Exhaust energy can be introduced into the cylinder via exhaust gas retention, using negative valve overlap (NVO) $[5,16]$. Engine operated in the NVO mode develops a specific cycle. Exhaust gas is trapped in the cylinder via early exhaust valve closing (EVC). Afterwards, residuals are re-compressed during the NVO period. Intake valve opening (IVO) is delayed as well. High amounts of trapped residuals increase mixture enthalpy, and thus enable auto-ignition of gasoline at low compression ratios.
However, in residual affected HCCI engines stable combustion can be achieved only in a narrow range of loads [4]. Low loads are limited by high fuel dilution, as under low exhaust temperature, internal EGR must be increased [2]. To achieve high loads it is necessary to increase volumetric efficiency. It implies reduction of the amount of trapped residuals, thus resulting in insufficient heating of the charge [11].

Urushihara et al. [10] proposed a combined spark ignition and HCCI concept, where the additional energy required for gasoline auto-ignition was provided by the combustion of some portion of a stratified mixture ignited by spark discharge. The obtained SACI (spark assisted compression ignition) combustion widened the high load limit of an engine, however excessive $\mathrm{NO}_{x}$ emissions were observed. Xie et al. [12] and Yun et al. [15] applied variable valve timings to control both the PRR and emissions under spark assisted HCCI combustion. The use of high positive valve overlap provided an EGR rate sufficient for reducing combustion rates. Additionally, high volumetric efficiency was also achieved. Yun et al. [15] achieved $1 \mathrm{MPa}$ in indicated mean effective pressure (IMEP) while maintaining acceptable levels of PRR and emissions. Olesky et al. [8] demonstrated that advanced spark discharge reduces $\mathrm{NO}$ emissions despite increasing the fuel fraction burned by flame propagation. The experiments were performed for a stoichiometric mixture, and the reduction in $\mathrm{NO}_{\mathrm{x}}$ emissions was attributed to a decrease in peak in-cylinder temperature.

The purpose of the current study is identification of the effects of spark discharge on HCCI combustion. In particular original procedure for fitting experimental heat release rates with double Wiebe function was applied. This approach enabled us to split combustion model between flame propagation and volumetric combustion.

\section{Experimental test stand}

A single-cylinder research engine was installed on a test bed equipped with a direct current dynamometer. The test stand is shown in Fig. 1. The engine was equipped with a mechanical variable valvetrain to enable the control of valve lifts and 
timings. The cams provided maximum valve lifts of $9.4 \mathrm{~mm}$ and valve opening durations of $235^{\circ} \mathrm{CA}$. The valve lifts were adjusted using the hydraulic mechanism, described in detail in [3]. The effect of reduction of valve lifts was similar to the effect which could be achieved by increasing the clearance between the cam and the valve tappet. Thus, this mechanism varied both the valve lift and opening duration. Additionally, the valvetrain was equipped with mechanical timing adjusters, which enabled rotation of the camshaft sprockets in relation to camshafts.

The research engine had a bowl-shaped combustion chamber located in the engine head. The piston face was protruding on its perimeter and it approached the cylinder head closely at top dead center (TDC), which generated a certain amount of squish. Fuel was applied into the cylinder using a side-mounted single-stream swirl-type injector. The main parameters of the engine are specified in Table 1.

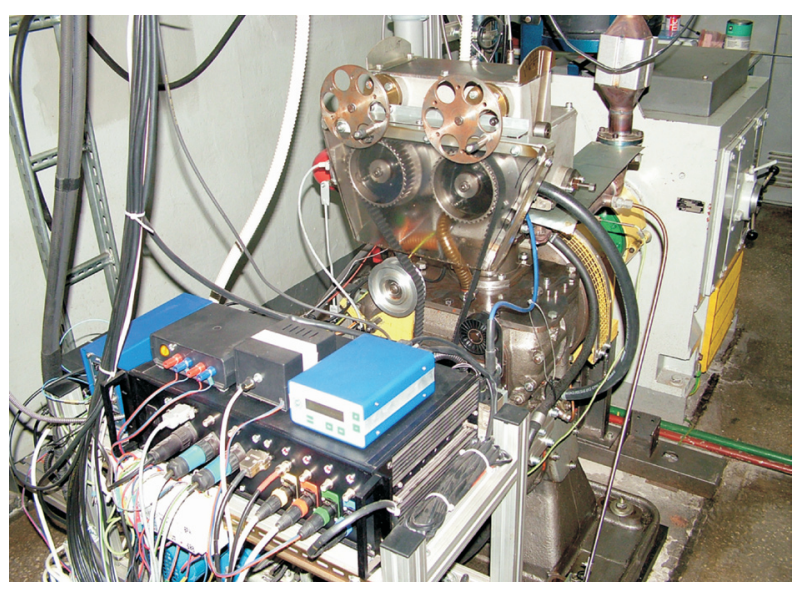

Fig. 1. Test stand used in the experiments

The engine control system was based on in-house PC software connected with a real-time timing module which governed not only injection timings and durations, but also spark generation.

The engine test bench was equipped with all necessary measurement and control instruments. Fuel consumption was measured using a fuel balance and intake airflow was measured with a thermal mass flow meter. The engine was also equipped with a set of pressure and temperature transducers in order to control the thermodynamic conditions of all media, intake, exhaust, cooling liquid etc. In-cylinder pressure was measured with the use of a miniature pressure transducer that was installed directly in the engine head. The pressure and other crank angle (CA) based parameters were recorded with a constant angular resolution of $0.1^{\circ} \mathrm{CA}$.

Table 1. Single cylinder research engine specifications

\begin{tabular}{|l|c|}
\hline Displaced volume & $498.5 \mathrm{~cm}^{3}$ \\
\hline Cylinder diameter & $84 \mathrm{~mm}$ \\
\hline Piston stroke & $90 \mathrm{~mm}$ \\
\hline Compression ratio & 11.7 \\
\hline No of valves & 2 \\
\hline Fuel injector & Solenoid actuated swirl-type \\
\hline Fuel-rail pressure & $11 \mathrm{MPa}$ max. \\
\hline
\end{tabular}

\section{Experimental conditions and procedure}

The engine was fuelled with pump-grade European commercial gasoline from a single batch. The experiments were conducted at a constant crankshaft rotational speed of $1500 \mathrm{rev} / \mathrm{min}$. The cooling liquid temperature at the engine outlet was maintained at $90^{\circ} \mathrm{C} \pm 1$. The engine was naturally aspirated and the intake air temperature was approx. $40^{\circ} \mathrm{C}$. The valvetrain was strategically set to achieve negative valve overlap and internal EGR. Valve timings and lifts are provided in Table 2. In order to simplify imaging of the valve timings, all values are provided in crank angle degrees after TDC, where zero is during NVO. Fuel was introduced into the cylinder during NVO to provide homogeneous charge. Fuel rail pressure was set to $10 \mathrm{MPa}$. The experiments were performed at stoichiometric mixture. Under investigated conditions engine load expressed by IMEP was approximately $0.4 \mathrm{MPa}$. The engine was run as autonomous HCCI, without spark discharge, and with spark discharge applied at variable timing.

The recorded pressure data were analyzed with the use of in-house software, where the measured pressure traces were utilized as boundary conditions for zero-dimensional models of gas exchange and combustion. The aim of modeling was to provide cycle-by-cycle composition of in-cylinder fluid and, thus, a more detailed analysis of combustion evolution. Detailed description of the engine model can be found in [3].

Table 2. Valvetrain settings

\begin{tabular}{|l|c|}
\hline Intake valve opening (IVO) & $83^{\circ} \mathrm{CA}$ \\
\hline Intake valve closing (IVC) & $213^{\circ} \mathrm{CA}$ \\
\hline Intake valve lift & $3.6 \mathrm{~mm}$ \\
\hline Exhaust valve opening (EVO) & $521^{\circ} \mathrm{CA}$ \\
\hline Exhaust valve closing (EVC) & $640^{\circ} \mathrm{CA}$ \\
\hline Exhaust valve lift & $2.9 \mathrm{~mm}$ \\
\hline
\end{tabular}

Combustion evolution was analyzed using net heat release rate (HRR) traces, computed on the basis of the first law of thermodynamics in the following form:

$$
\mathrm{HRR}=\frac{\gamma}{\gamma-1} \mathrm{pdV}+\frac{1}{\gamma-1} \mathrm{Vdp}
$$

where $\mathrm{p}$ is in-cylinder pressure, $\mathrm{V}$ is volume, and the ratio of specific heats $\gamma$ was calculated according to the instantaneous temperature and mixture composition in the cylinder.

The metrics representing the combustion timing were expressed as crank angle at the characteristic percentage values of standardized cumulative heat release, which is conventionally equated with the mass fraction burned (MFB) of fuel. All traces shown in this study are ensemble average computed from 100 consecutive engine cycles.

\section{Experimental results}

In-cylinder pressure curves shown in Fig. 2 reveal effects of spark discharge on combustion timing. Obviously, early spark discharge resulted in earlier start of combustion. Additionally, ignition advance resulted in increase of peak pressures, as their locations approached TDC. To provide 
more insight into combustion evolution, Fig. 3 shows net heat release curves for investigated conditions. It should be noted that peak heat release rates are not monotonic versus spark advance. The highest values were observed for moderate spark timings. It is plausible, as auto-ignition was advanced, whereas high fraction of slow flame propagation combustion could not be observed. It has been already demonstrated by Wang et al. [11] that at conditions where auto-ignition is attainable, spark assist had a little effect on combustion. Nevertheless, application of spark could extend operation range of the engine. In the current study the engine was operated close to the misfire limit where auto-ignition appeared near TDC. It is plausible, that further reduction of internal EGR would be applicable, which would extend high load limit. It was demonstrated already by Olesky et al. [7] that effect of spark ignition is increasing for reduced EGR rates.

Reduction of peak HRRs at early ignition did not provide reduction of PRRs, as shown in Fig. 4. As combustion was developing during compression stroke, the effect of compression additionally increased PRR. Furthermore, early start of combustion increased specific fuel consumption, as shown in Fig. 5.

It should be noted that $\mathrm{NO}_{\mathrm{x}}$ emissions were found to be affected by spark discharge to a very small extent, as shown in Fig. 5. Ignition advance from TDC to $40^{\circ} \mathrm{CA}$ before TDC

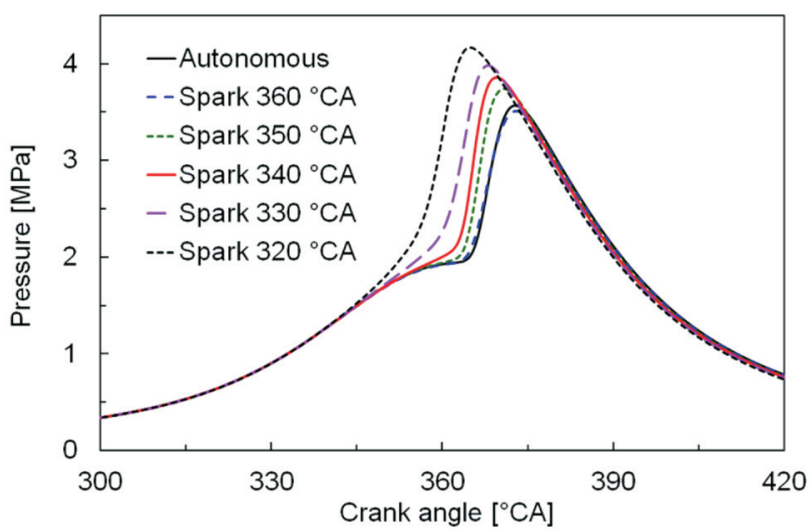

Fig. 2. In-cylinder pressure for autonomous HCCI and variable spark ignition timings

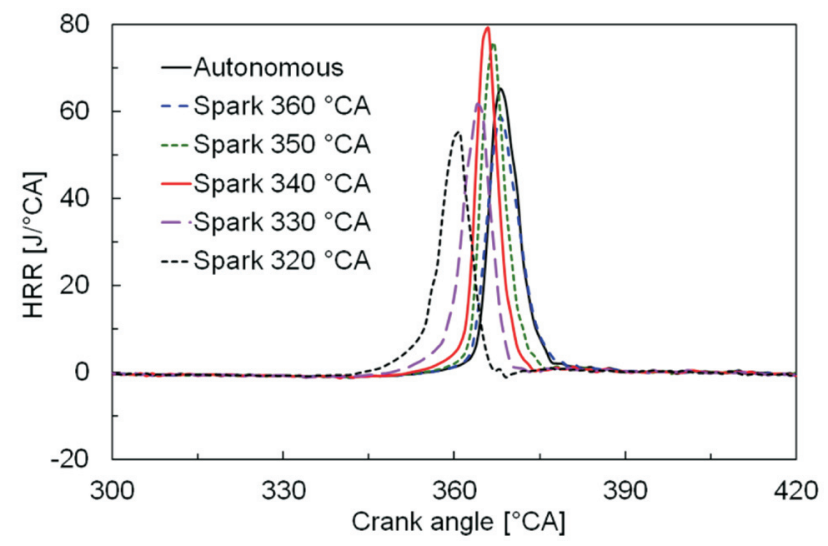

Fig. 3. Heat release rates for autonomous HCCI and variable spark ignition timings

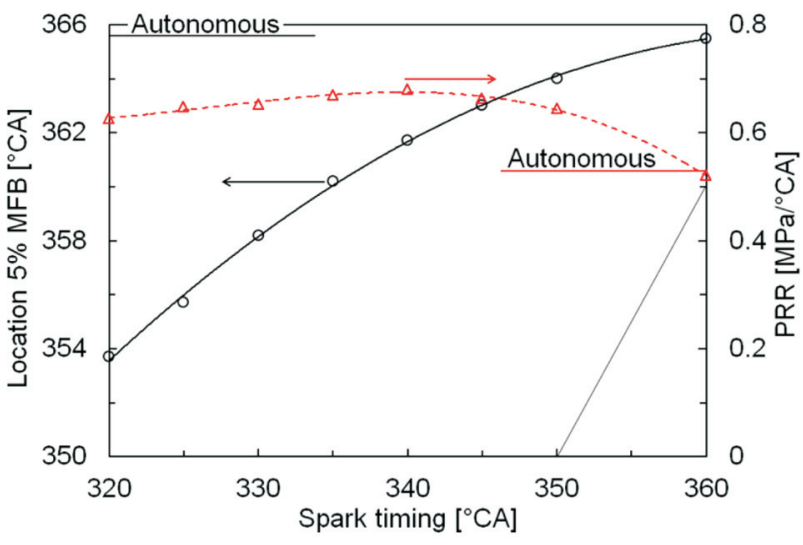

Fig. 4. Locations of 5\% MFB and PRRs with respect to spark ignition timing

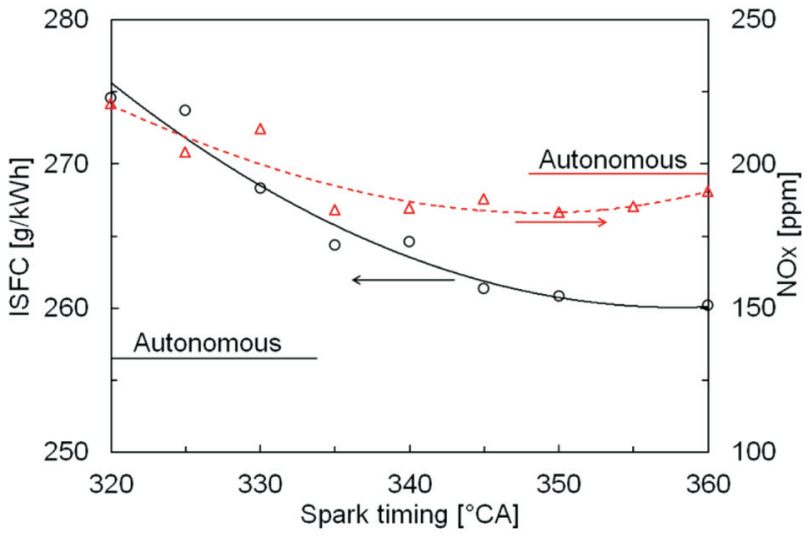

Fig. 5. ISFC and concentrations of $\mathrm{NO}_{\mathrm{x}}$ with respect to spark ignition timing

increased emissions less than 20\%. Comparison of Fig. 2 and Fig. 5 reveals good agreement between peak pressures and $\mathrm{NO}_{\mathrm{x}}$ concentrations. This observation suggests that there is no effect of flame propagation on $\mathrm{NO}_{x}$ production. Instead, $\mathrm{NO}_{\mathrm{x}}$ production appears to be controlled by peak temperatures during HCCI combustion phase. Plausible explanation of this phenomenon would be small fraction of fuel burned by flame propagation. Net HRR traces shown in Fig. 3 confirm this presumption. Double stage combustion could be observed solely for $40{ }^{\circ} \mathrm{CA}$ spark advance. However, experimental traces cannot provide quantitative data, how combustion is split between flame propagation and volumetric process. In order to estimate flame propagation fractions, in the next section, double Wiebe functions were fitted to experimental MFB curves.

\section{Estimation of combustion model}

A dedicated algorithm was elaborated to fit experimental MFB traces with double Wiebe model. MFB as a function of crank angle $\varphi$ was computed using the following Wiebe formula:

$$
\mathrm{MFB}=1-\exp \left[-6.908\left(\frac{\varphi-\mathrm{SOC}}{\mathrm{EOC}-\mathrm{SOC}}\right)^{\mathrm{m}+1}\right]
$$


where SOC and EOC are crank angles at start and at end of combustion, respectively and $\mathrm{m}$ is shape parameter. Double Wiebe function was computed as weighted sum of two independent MFB traces using spark ignition fraction as a parameter, which distinguished between fuel consumption by flame propagation and by volumetric combustion. Thus, it was necessary to estimate seven combustion parameters. Despite SACI, this approach is common for stratified compression ignition combustion [1] or dual-fuel spark ignition combustion [14].

During the estimation of parameters, start of combustion and end of combustion locations were identified on the basis of experimental MFB traces. For estimation of remaining parameters heuristic successive approximation algorithm was implemented. The algorithm compared combustion models, which incorporated all combinations of the parameters, with experimental data. The selected representative combustion model was one, which exhibited the smallest mean square error.

For autonomous HCCI combustion (without spark assist) experimental MFB was fitted with single Wiebe function, shown in Fig. 6a. Combustion duration was $17{ }^{\circ} \mathrm{CA}$ and shape parameter $m$ was 2.6 . It can be noted that fitting experimental data with single Wiebe function was not accurate at the beginning stage of combustion as well as at the end of the process.

It was already shown in Fig. 3 that for spark assisted combustion double-stage processes were not clearly revealed by HRR curves. However, transition from flame propagation to volumetric combustion can be observed as points with the narrowest bent of MFB curves. Fitting experimental data with double Wiebe provided very good accuracy, as shown in Figs. 6b and 6c. However, for both spark ignition timings of $340^{\circ} \mathrm{CA}$ and $320^{\circ} \mathrm{CA}$ estimated values of mass fraction burned by flame propagation were the same and amounted to $9 \%$. These observations explain negligible effect of spark assist on $\mathrm{NO}_{\mathrm{x}}$ emissions. Obtained results are consistent with findings of Zigler et al. [17]. Using combustion imaging they demonstrated that the initial formation of the reaction fronts are not significant sources of heat release. Nevertheless, spark ignition controls HCCI combustion timing.

It should be noted that HCCI heat release profiles shown in Figs. $6 \mathrm{~b}$ and $6 \mathrm{c}$ differ. For ignition timing 340 ${ }^{\circ} \mathrm{CA}$ start of HCCI combustion is very steep. It is plausible, as auto-ignition was triggered near TDC, where both high temperature and pressure appeared. In contrast, for earlier spark ignition (Fig. 6c) HCCI combustion started slowly, similarly to the profile observed for autonomous operation. In this case, auto-ignition was triggered as a result of heating by flame front, much earlier, before conditions for auto-ignition appeared in whole combustion chamber. In other words HCCI combustion could start locally, in the area heated by the flame front. It is worth notice, that the identified combustion parameters are consistent with experimental PRR trends, shown in Fig. 4.

\section{Conclusions}

A gasoline engine with a fully variable valvetrain and direct fuel injection was used for the analysis of spark

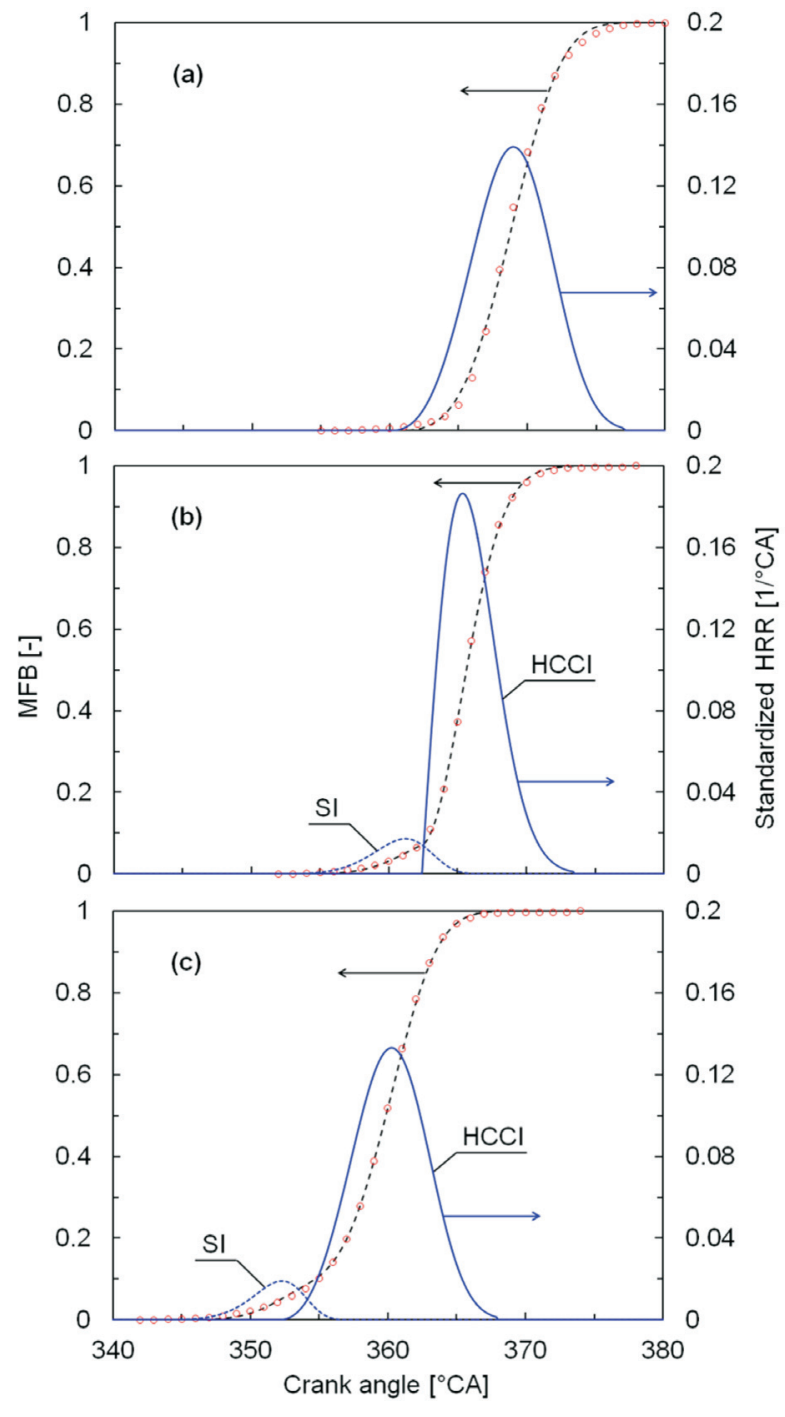

Fig. 6. Experimental MFB traces with fitted combustion models: a) autonomous $\mathrm{HCCI}$, b) spark ignition timing $340{ }^{\circ} \mathrm{CA}$, c) spark ignition timing $320^{\circ} \mathrm{CA}$. Circles show experimental data.

ignition effects on residual effected HCCI combustion. An investigation was carried out under stoichiometric conditions. The engine was run as autonomous HCCI and spark assisted HCCI with variable spark timings. The findings of this study can be summarized as follows:

1. Application of spark assist to HCCI engine can be used for controlling combustion timing. Heat release by flame propagation triggers $\mathrm{HCCI}$ combustion of the unburned mixture, thus engine operation could be extended to regimes, where heat introduced with trapped residuals is insufficient to achieve autonomous HCCI combustion.

2. It was found that under investigated conditions spark ignition advance had negligible effect on $\mathrm{NO}_{x}$ emissions. Instead, the emissions were correlated with peak pressures. Thus, $\mathrm{NO}_{\mathrm{x}}$ were created mainly during $\mathrm{HCCI}$ combustion stage.

3. Fitting experimental heat release traces with double Wiebe models showed that only up to $10 \%$ of heat is released by flame propagation. Early stage of combustion was not a source of $\mathrm{NO}_{x}$ emissions. 
4. It was found that HCCI heat release was not changing monotonically with spark advance. Peak HRR values were obtained for moderate spark advance, where HCCI combustion was triggered near TDC.

\section{Acknowledgements}

The research was funded by the Polish National Science Centre under grant 2012/05/B/ST8/00077. Authors also acknowledge financial support from MINECO (Spain) under grant ENE201340644-R.

$\begin{array}{ll}\text { Nomenclature } \\ \text { CA } & \text { Crank angle } \\ \text { EGR } & \text { Exhaust gas re-circulation } \\ \text { HCCI } & \text { Homogeneous charge compression ignition } \\ \text { HRR } & \text { Heat release rate } \\ \text { ISFC } & \text { Indicated specific fuel consumption } \\ \text { MFB } & \text { Mass fraction burned } \\ \text { NVO } & \text { Negative valve overlap } \\ \text { PRR } & \text { Pressure rise rate } \\ \text { SACI } & \text { Spark assisted compression ignition } \\ \text { TDC } & \text { (Piston) top dead center }\end{array}$

\section{Bibliography}

[1] Denis-Vidal L., Cherfi Z., Talon V., Brahmi H. Parameter identifiability and parameter estimation of a diesel engine combustion model. Journal of Applied Mathematics and Physics, 2014;2131-137.

[2] Hunicz J. An experimental study of negative valve overlap injection effects and their impact on combustion in a gasoline HCCI engine. Fuel 2014;117:236-250.

[3] Hunicz J. On cyclic variability in a residual effected $\mathrm{HCCI}$ engine with direct gasoline injection during negative valve overlap. Mathematical Problems in Engineering 2014, Article ID 359230 .

[4] Hunicz J., Medina A., Litak G., Curto-Risso P.L., GuzmánVargas L. Effects of direct fuel injection strategies on cycle-by-cycle variability in a gasoline homogeneous charge compression ignition engine: sample entropy analysis. Entropy 2015;17:539-559.

[5] Lavy J., Dabadie J.Ch., Angelberger Ch., Duret P. et al. Innovative ultra-low $\mathrm{NO}_{\mathrm{x}}$ controlled auto-ignition combustion process for gasoline engines: the 4-SPACE project. SAE Technical Paper 2000-01-1837; 2000.

[6] Najt P.M., Foster D.E. Compression-ignited homogeneous charge combustion. SAE Technical Paper 830264; 1983.

[7] Olesky L.M., Lavoie G.A., Assanis D.N., Wooldridge M.S., Martz J.B. The effects of diluent composition on the rates of HCCI and spark assisted compression ignition combustion. Applied Energy 2014;124:186-198.

[8] Olesky L.M., Martz J.B., Lavoie G.A., Vavra J., Assanis D.N., Babajimopoulos A. The effects of spark timing, unburned gas temperature, and negative valve overlap on the rates of stoichiometric spark assisted compression ignition combustion. Applied Energy 2013;105:407-417.

[9] Onishi S., Jo S., Shoda K., Jo P., Kato S. Active thermo-atmosphere combustion (ATAC) - a new combustion process for

Jacek Hunicz, DSc., DEng. - Professor in the Faculty of Mechanical Engineering at Lublin University of Technology.

e-mail:j.hunicz@pollub.pl

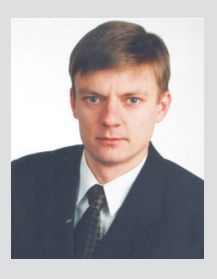

Pawel Kordos, DEng. - Doctor in the Faculty of Mechanical Engineering at Lublin University of Technology.

e-mail:p.kordos@pollub.pl internal combustion engines. SAE Technical Paper 790501; 1979.

[10] Urushihara T., Yamaguchi K., Yoshizawa K., Itoh T. A study of a gasoline-fueled compression ignition engine. Expansion of HCCI operation range using SI combustion as a trigger of compression ignition. SAE Technical Paper 2005-01-0180; 2005.

[11] Wang Z., Wang J-X., Shuai S-J., Tian G-H., An X., Ma Q-J. Study of the effect of spark ignition on gasoline HCCI combustion. Proceedings of the Institution of Mechanical Engineers, Part D: Journal of Automobile Engineering 2006;220:817-825.

[12] Xie H., Li L., Chen T., Yu W., Wang X., Zhao H. Study on spark assisted compression ignition (SACI) combustion with positive valve overlap at medium-high load. Applied Energy 2013;101:622-633.

[13] Yao M., Zheng Z., Liu H. Progress and recent trends in homogeneous charge compression ignition (HCCI) engines. Progress in Energy and Combustion Science 2009;35:398-437.

[14] Yeliana, Cooney C., Worm J., Michalek D., Naber J. Wiebe function parameter determination for mass fraction burn calculation in an ethanol-gasoline fuelled SI engine. Journal of KONES Powertrain and Transport 2008;15:567-574.

[15] Yun H., Wermuth N., Najt P. High load HCCI operation using different valving strategies in a naturally-aspirated gasoline HCCI engine. SAE International Journal of Engines 2011;4:1190-1201.

[16] Zhao H., Li J., Ma T., Ladommatos N. Performance and analysis of a 4-stroke multi-cylinder gasoline engine with CAI combustion. SAE Technical Paper 2002-01-0420; 2002.

[17] Zigler B.T., Keros P.E., Helleberg K.B., Fatouraie M., Assanis D., Wooldridge M.S. An experimental investigation of the sensitivity of the ignition and combustion properties of a single-cylinder research engine to spark-assisted HCCI. International Journal of Engine Research 2011;12:353-375.

Michał Gęca, MEng. - PhD student in the Faculty of Mechanical Engineering at Lublin University of Technology.

e-mail: michal.geca@pollub.pl

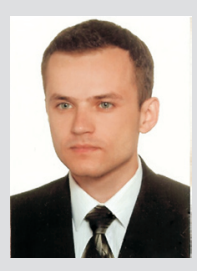

Alejandro Medina, PhD. - Professor in the Department of Applied Physics at University of Salamanca.

e-mail: amd385@usal.es 